\title{
Vascular Endothelial Growth Factor Expression, $\beta$-Catenin Tyrosine Phosphorylation, and Endothelial Proliferative Behavior: A Pathway for Transformation?
}

\author{
Neta Ilan, Adeline Tucker, and Joseph A. Madri \\ Department of Pathology, Yale University School of Medicine, New Haven, Connecticut
}

SUMMARY: The hypothesis that tumor growth is angiogenesis dependent has been documented by a considerable body of direct and indirect experimental data and has generated intense basic and pharmaceutical-related interest. In contrast, the study of endothelial cell tumors has been modest by comparison. Hemangioma is the most common tumor of any kind seen in infancy and also, perhaps, the least understood. We compared a mouse hemangioma-derived cell line (EOMA) and primary human endothelial cells (HUVEC) for their proliferative behavior and molecular alterations. EOMA cells intrinsically expressed vascular endothelial growth factor (VEGF), which acts in an autocrine manner, resulting in an increase in CD1 expression and cell proliferation, both of which were inhibited by anti-VEGF neutralizing antibodies. Such an autocrine loop is supported by constitutive VEGF receptor (Flk-1) tyrosine phosphorylation, Flk-1 and Flt-1 nuclear localization, and mitogen-activated protein kinase activation. $\beta$-catenin was also found to exhibit significant nuclear localization and constitutively associate with Flk-1 and Flt-1 in EOMA cells but much less so in HUVEC, and immunoprecipitated Flk- 1 was able to phosphorylate purified $\beta$-catenin in an immune complex kinase assay. EOMA cells were also noted to express reduced levels of $\mathrm{N}$-cadherin and $\gamma$-catenin compared with HUVEC. Interestingly, sequestration of endogenous VEGF in EOMA cultures resulted in a dramatic decrease in nuclear $\beta$-catenin and a reduction in CD1 levels, whereas addition of exogenous VEGF elicited increased nuclear $\beta$-catenin localization and increased CD1 levels in HUVEC. The possible contributions of VEGF signaling pathways, cell junction component expression levels, and phosphorylation states to endothelial cell transformation and proliferation are discussed. (Lab Invest 2003, 83:1105-1115).

$T$ umor angiogenesis has been shown to play a major role in the growth of carcinomas, sarcomas, and lymphoid neoplasms, which has led to intensive investigations in the areas of antiangiogenesis and antiangiogenic therapy. In contrast, the study of endothelial cell tumors has been modest by comparison. Although it is well-recognized that endothelial cell tumors are known to cause significant morbidity and mortality, their pathogenesis remains incompletely understood (Marchuk, 2001). The importance of selected growth factors in the processes of vasculogenesis, angiogenesis, vessel stabilization, and involution has led to an appreciation of their potential importance in influencing endothelial tumor biology (Cross and Claesson-Welsh, 2001; Ferrara and Alitalo, 1999; Keshet and Ben-Sasson, 1999). Hashimoto et al (1995) demonstrated the presence of vascular endothelial growth factor (VEGF) and Flt-1 mRNA and

DOI: 10.1097/01.LAB.0000083531.84403.8B

Received May 29, 2003.

This work was supported in part by USPHS Grants R37-HL28373 and PPG-DK38979 (to JAM) and a Reed Foundation Fellowship in Vascular Biology (to NI). Current address for Dr. Ilan: Department of Vascular Biology, Rappaport Family Institute for Research in the Medical Sciences, The Technion Institute of Technology, P. O. Box 9697, Haifa 31096, Israel.E-mail:netailan@tx.technion.ac.il

Address reprint requests to: Dr. J. A. Madri, Department of Pathology, Yale University School of Medicine, 310 Cedar Street, New Haven, Connecticut 06520.E-mail: joseph.madri@yale.edu. proteins in a series of angiosarcoma cases. In a later study, Flt-1 (VEGFR-1), Flk-1 (VEGFR-2), Tie, and VEGF mRNAs were demonstrated to be up-regulated in hemangioblastomas (Bohling et al, 1996; Hatva et al, 1996). Recently, Arbiser et al (2000) have shown that expression of VEGF121 in an endothelial cell line led to the development of slow-growing endothelial tumors having the phenotype of well-differentiated angiosarcomas. These studies and others (Maru et al, 2000; Muhlner et al, 1999) support the concept that increased expression of VEGF in endothelial cells can be responsible for endothelial cell transformation via an autocrine/paracrine pathway. The pathways and mechanisms involved in this VEGF-mediated process are complex and only incompletely understood. Several investigators have shown that VEGF elicits changes in endothelial cell-cell contacts and permeability, both of which are associated with changes in the phosphorylation states of a variety of cell adhesion proteins (Abedi and Zachary, 1997; Esser et al, 1998; Ilan et al, 1999; Kevil et al, 1998), which in turn have the capability of modulating endothelial permeability, proliferation, migration, survival, and differentiation (Carmeliet et al, 1999; Lampugnani and Dejana, 1997).

In this report we examine the associations between the endogenous expression of VEGF, tyrosine phosphorylation of VEGF receptors, tyrosine phosphorylation and cellular localization of $\beta$-catenin, and proliferative behavior in hemangioma-derived EOMA cells and primary endothelial cells. 


\section{Results}

Proliferation Rates, $\beta$-Catenin Phosphorylation, and Flk-1 Phosphorylation of EOMA and Human Umbilical Vein Endothelial Cells (HUVEC) Are Dependent upon Levels of Endogenous VEGF

Recent observations indicated that VEGF stimulates tyrosine phosphorylation of endothelial cell adhesion components such as platelet-endothelial cell adhesion molecule-1 (PECAM-1), VE-cadherin, and catenin family members (Esser et al, 1998; Ilan et al, 1999); this possibly contributes to the regulation of blood vessel permeability (Esser et al, 1998). To further study the interaction between VEGF, VEGF receptors, and cell adhesion components, we immunoprecipitated endothelial cell lysates with anti-Flt-1 and Flk-1 antibodies, followed by $\beta$-catenin immunoblotting (Fig. 1A). $\beta$-catenin was found to be associated with both VEGF-receptors in hemangioma-derived EOMA cells and to a much reduced level with Flk-1 in HUVEC ( $\mathrm{Hu}$, Fig. 1A). To further compare Flt-1/Flk-1 expression profiles in these two cell lines, HUVEC and EOMA cell
A

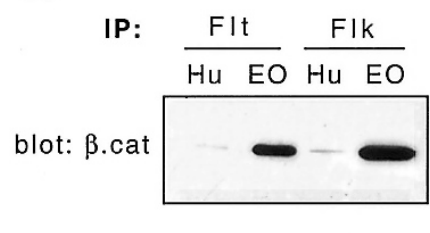

C
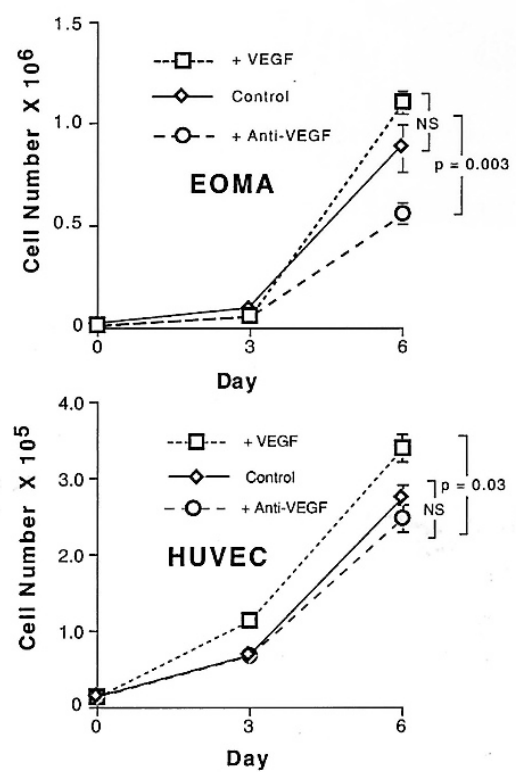

B

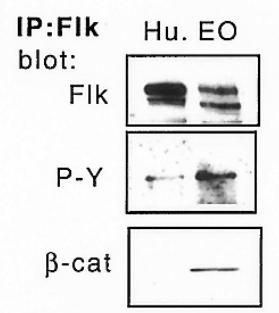

blot:

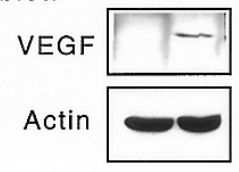

E

IP kinase assay

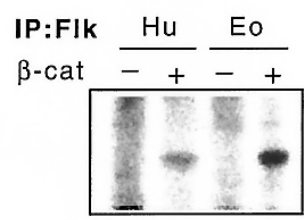

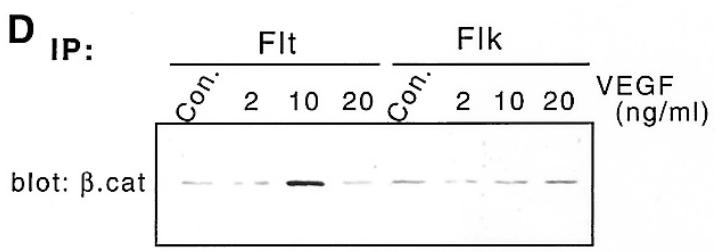

Figure 1.

VEGFR-1 (Flt-1) and VEGFR-2 (Flk-1) associate with and tyrosine phosphorylate $\beta$-catenin. A, Western blots of immunoprecipitates of HUVEC (Hu) and EOMA cell (EO) Iysates with antibodies directed against VEGFR-1 (FIt-1) and VEGFR-2 (FIk-1) reveal differentially coprecipitated $\beta$-catenin. EOMA cells display coprecipitated $\beta$-catenin, whereas negligible amounts of $\beta$-catenin were noted in the HUVEC immunoprecipitates. B, HUVEC (Hu) and EOMA (EO) cell Iysates were immunoprecipitated with anti-Flk-1 antibodies, followed by Flk-1 (upper panel) Western blot analysis. The same membrane was stripped and reprobed with anti-phosphotyrosine ( $P-Y$, second panel) and anti- $\beta$-catenin (third panel) antibodies. HUVEC and EOMA total cell lysates were immunoblotted with antivascular endothelial growth factor (anti-VEGF) antibodies (fourth panel), stripped, and reprobed with anti-actin (lower panel) antibodies. Note the robust VEGF expression, FIk-1 tyrosine phosphorylation, and association with $\beta$-catenin in EOMA cells, compared with the modest Flk- 1 tyrosine phosphorylation and nondetectable $\beta$-catenin association and VEGF expression in HUVEC cells. C, HUVEC and EOMA cell proliferation rates were assessed in the absence (diamonds) and presence of VEGF (squares) and anti-VEGF-neutralizing antibody (circles). Cells $\left(4.0 \times 10^{4}\right.$ per $60-\mathrm{mm}$ Petri dish) were plated and cultured for 6 days in the absence or presence of $10 \mathrm{ng} / \mathrm{ml}$ VEGF or anti-VEGF. Triplicate samples were counted on days 0,3 , and 6 . NS denotes a P value of $\geq 0.05$. D, HUVEC were left unstimulated or stimulated with VEGF at the indicated concentrations for 15 minutes and cell lysates were immunoprecipitated with anti-Flt-1 and Flk-1 antibodies, followed by $\beta$-catenin immunoblotting. Note $\beta$-catenin association with Flt-1, but not Flk-1, in a manner that is VEGF dose dependent. E, HUVEC and EOMA cell cultures were immunoprecipitated for Flk-1 as in B, and the resulting precipitates were subjected to an in vitro kinase assay for recombinant $\beta$-catenin in the presence of $\left[\gamma^{-}{ }^{-32}\right.$ P]ATP. Precipitated Flk-1 from HUVEC and EOMA both phosphorylated the recombinant $\beta$-catenin. However, the EOMA-derived material elicited a more robust phosphorylation compared with the HUVEC-derived precipitate, in agreement with higher PY levels noted in B (second panel). 
lysates were immunoprecipitated for Flk-1, followed by Flk-1 immunoblotting (Fig. 1B, first panel). Interestingly, Flk-1 expression levels were higher in HUVEC than in EOMA, suggesting that expression levels per se are not the reason for the differential association with $\beta$-catenin noted in Figure $1 \mathrm{~A}$. Moreover, Flk-1 tyrosine phosphorylation levels were significantly higher in EOMA cells than in HUVEC, as judged after stripping and reprobing the same membrane with antiphosphotyrosine antibodies (Fig. 1B, second panel). $\beta$-catenin was found to be associated with Flk- 1 to a much greater degree in cell lysates (Fig. 1B, third panel), in agreement with our initial observations (Fig. 1A). The constitutively active Flk-1 molecules are likely a result of the presence of VEGF. Indeed, immunoblot analysis clearly revealed VEGF expression by EOMA cells but not HUVEC (Fig. 1B, fourth panel), in agreement with immunohistochemical staining results documented in previous studies (Takahashi et al, 1994). Thus, in EOMA cells, VEGF apparently acts in an autocrine manner, constitutively activating its receptors and initiating downstream effects such as association with and phosphorylation of $\beta$-catenin (Fig. 1, A and B; Ilan et al, 1999). Interestingly, such an autocrine loop also results in Flk nuclear translocation (see below), suggesting other possible signaling modes.

To further correlate VEGF expression and proliferative behavior, VEGF or VEGF-neutralizing antibodies were added to HUVEC and EOMA cell cultures (Fig. 1C). As would be expected, the EOMA proliferative rate was not affected by the addition of exogenous VEGF but was significantly reduced upon addition of neutralizing VEGF antibodies (Fig. 1C). In contrast, HUVEC proliferation was not appreciably affected by the addition of neutralizing VEGF antibodies but was significantly increased upon addition of exogenous VEGF (Fig. 1C). We recently reported that in HUVEC, VEGF induces $\beta$-catenin tyrosine phosphorylation in a dose-dependent manner that peaks at $10 \mathrm{ng} / \mathrm{ml}$ (Ilan et al, 1999). Similarly, $\beta$-catenin was found to be associated with Flt-1 (Fig. 1D) in a dose-responsive manner that perfectly mimics $\beta$-catenin tyrosine phosphorylation (Ilan et al, 1999). Lack of $\beta$-catenin association with Flk-1 under these culture conditions may be a result of differences in the receptors' affinities toward VEGF (Ferrara and Davis-Smyth, 1997) as evidenced by the modest association of $\beta$-catenin with Flk-1 at the highest VEGF dosage used $(20 \mathrm{ng} / \mathrm{ml})$ (Fig. 1D).

To further demonstrate $\beta$-catenin phosphorylation by Flk-1, HUVEC and EOMA cell lysates were first immunoprecipitated for Flk-1 and kinase assays were performed in the absence $(-)$ or presence $(+)$ of purified, recombinant $\beta$-catenin and radiolabeled $\left({ }^{32} \mathrm{P}\right)$ phosphate (Fig. 1E). Immunoprecipitated Flk-1 from both HUVEC and EOMA cells was able to phosphorylate $\beta$-catenin. However, $\beta$-catenin phosphorylation was significantly higher in the EOMA compared with the HUVEC Immunoprecipitation, in agreement with the constitutively tyrosine phosphorylated Flk-1 observed in EOMA cells (Fig. 1B, second panel). Further, coprecipitation of tyrosine-phosphorylated $\beta$-catenin with immunoprecipitation of Flt-1 in both EOMA and HUVEC, albeit much less in HUVEC, suggests that Flt-1 is also capable of tyrosine phosphorylating $\beta$-catenin (data not shown).

\section{After Activation by Endogenous VEGF, EOMA FIk-1 Translocates to the Nucleus}

Flk-1 was recently noted to be rapidly internalized (Dougher and Terman, 1999) and translocated to the nucleus (Feng et al, 1999) upon VEGF stimulation. Given the observed autocrine VEGF loop leading to an active Flk-1 in EOMA cells, we were interested in determining Flk-1 and Flt-1 localization in these cells. Immunofluorescent staining and confocal microscopic analyses revealed that most of the Flk-1 and Flt-1 immunoreactivity (not shown) was localized to the nuclei of EOMA cells (Figs. 2, b and c, and 3, b to d) and is best demonstrated by the z-plane section confocal micrograph (Fig. 3d). This observation stands in contrast with Flk-I localization to areas of cell-cell contacts in HUVEC (Fig. 2, e and f; llan et al, 1999) and suggests that the autocrine VEGF loop in EOMA cells results in constitutive internalization, nuclear translocation, and possibly degradation of VEGF receptors. This may explain the lower Flk-1 (Fig. 1B, upper panel) and Flt-1 (not shown) expression levels observed in EOMA cells compared with HUVEC. Interestingly, $\beta$-catenin appeared to assume perinuclear and nuclear localization, colocalizing with Flk-1 (yellow fluorescence in Fig. 2c), and only a modest fraction of the $\beta$-catenin pool seems to be localized at cell-cell borders (Fig. 2, a and c). This localization pattern is in contrast to the predominately peripheral, cell border colocalization of $\beta$-catenin and Flk-1 observed in HUVEC (yellow fluorescence in Fig. 2, $d$ and f).

VEGF/Flk-1 internalization has been reported to be temperature dependent (Dougher and Terman, 1999). We therefore cultured EOMA cells at $4{ }^{\circ} \mathrm{C}$ for 3 hours before $\beta$-catenin and Flk-1 staining (Fig. 3, e to k). Preincubation of EOMA cells at $4{ }^{\circ} \mathrm{C}$ significantly reduced Flk-1 nuclear translocation (Fig. 3f). Instead, most of the Flk-1 immunoreactivity appeared in transport vesicles, probably caveolae (Feng et al, 1999) and is best demonstrated at high magnification (Fig. 3, i and $\mathrm{k}$ ). Moreover, preincubation at $4{ }^{\circ} \mathrm{C}$ resulted a significant change of $\beta$-catenin localization toward cell-cell borders (Fig. 3, e and g), which correlated with a decrease in $\beta$-catenin tyrosine phosphorylation levels (see below).

\section{EOMA Adhesion Components Are Either Absent or Tyrosine Phosphorylated}

Interestingly, in EOMA cells, cell-cell contacts were largely discontinuous and immature, as evident by $\beta$-catenin staining as a marker for cell adhesion components (Fig. 3a). Cell-adhesion integrity, however, was significantly improved upon preincubation at $4{ }^{\circ} \mathrm{C}$, as judged by $\beta$-catenin (Fig. 3 , e and g) and PECAM-1 staining (not shown). We were therefore interested to further characterize cell adhesion com- 

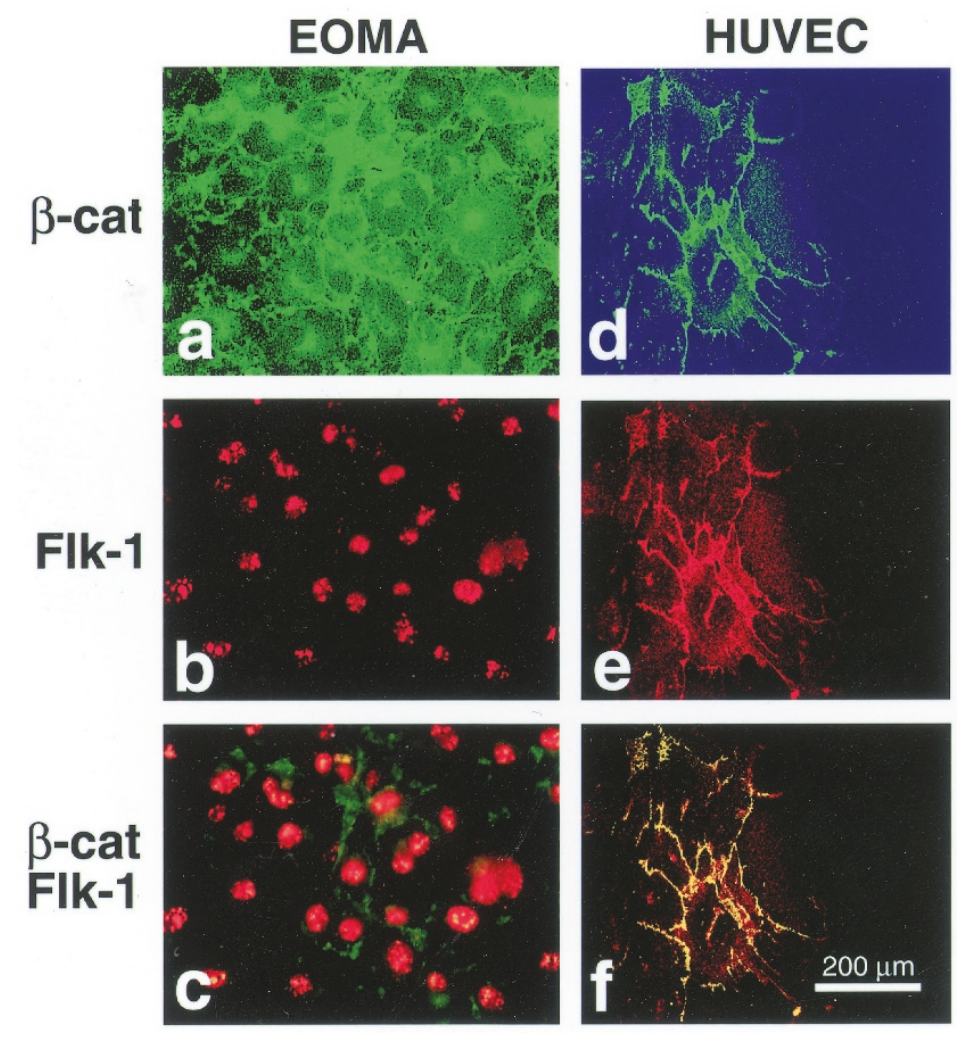

Figure 2.

Confocal immunofluorescence micrographs illustrating VEGFR-2 (Flk-1) nuclear localization in EOMA cells and HUVEC. EOMA cultures double labeled with anti- $\beta$-catenin and anti-Flk-1 antibodies exhibited a discontinuous peripheral staining pattern for $\beta$-catenin (a). In contrast, Flk-1 localization was found to be predominantly nuclear (b). The merged image of a and b revealed disparate, but partially colocalized, staining patterns (c). HUVEC cultures double labeled with anti- $\beta$-catenin and anti-Flk-1 antibodies exhibited a continuous peripheral staining pattern for $\beta$-catenin (d). In contrast to EOMA cells, Flk- 1 localization was also found to be predominantly peripheral (e). The merged image of $d$ and e revealed mostly a colocalized, peripheral staining pattern (f).

ponents in EOMA cells. $\mathrm{N}$-cadherin was undetectable (Fig. 4, second panel), and only residual $\gamma$-catenin expression levels were observed (Fig. 4, third panel) in EOMA cells, both of which were abundantly expressed in HUVEC. The ability of both antibodies to recognize the mouse molecules was confirmed with other mouse-derived endothelial cell extract (SVEC; not shown). Moreover, a robust increase in Src expression was observed in EOMA cells. Because p120 catenin was originally discovered as an Src substrate (Reynolds et al, 1989), and given the increase in Src expression in EOMA cells, we examined p120 tyrosine phosphorylation levels in HUVEC and EOMA cells. Both p120 (Fig. 4B, upper panel) and $\beta$-catenin (Fig. 4B, second panel; llan et al, 1999, 2000) were noted to be hyperphosphorylated on tyrosine resides in EOMA cells. Thus, cell adhesion components are either highly phosphorylated (ie, $\beta$-catenin, p120) or practically absent (ie, $\mathrm{N}$-cadherin, $\gamma$-catenin) in EOMA cells. Moreover, p120 hyperphosphorylation may suggest that the abundant Src is also active and contributing to the EOMA cell transformation. Interestingly, a decrease in the insoluble $\beta$-catenin tyrosine phosphorylation levels was noted upon preincubation of EOMA cells at $4{ }^{\circ} \mathrm{C}$ (Fig. $4 \mathrm{C}$, upper panel), whereas the soluble fractions were not affected. This correlates with the preservation of cell adhesion integrity observed at $4{ }^{\circ} \mathrm{C}$ (Fig. 3e). Several mechanisms could potentially contribute to catenin tyrosine phosphorylation: VEGF receptors and Src may be implicated. To distinguish between the two, EOMA cells were incubated with increasing concentrations of VEGFneutralizing antibodies and $\beta$-catenin tyrosine phosphorylation levels were analyzed (Fig. 4D). VEGFneutralizing antibodies at a concentration of $1 \mu \mathrm{g} / \mathrm{ml}$ resulted in a significant decrease in $\beta$-catenin (Fig. 1D, upper panel) but not p120 (Fig. 1 D, third panel) tyrosine phosphorylation levels. This observation may suggest that although VEGF stimulation contributes to $\beta$-catenin phosphorylation, Src is the major kinase responsible for p120 phosphorylation.

\section{VEGF Levels Determine $\beta$-Catenin Localization and Signaling Pathway Activation}

In light of the correlation of increased VEGF expression with an increased proliferation rate and nuclear localization of $\beta$-catenin in EOMA cells, we determined the effects of modulation of VEGF levels on the localization of $\beta$-catenin and the functional consequences of $\beta$-catenin's nuclear localization by assessing changes in CyclinD1 expression, a protein known to be regulated by transcriptionally active nuclear $\beta$-catenin complexed with TCF (Gotoh et al, 2003). Immunofluorescence analysis of EOMA cells revealed robust nuclear localization of $\beta$-catenin (Fig. 5A). Ad- 

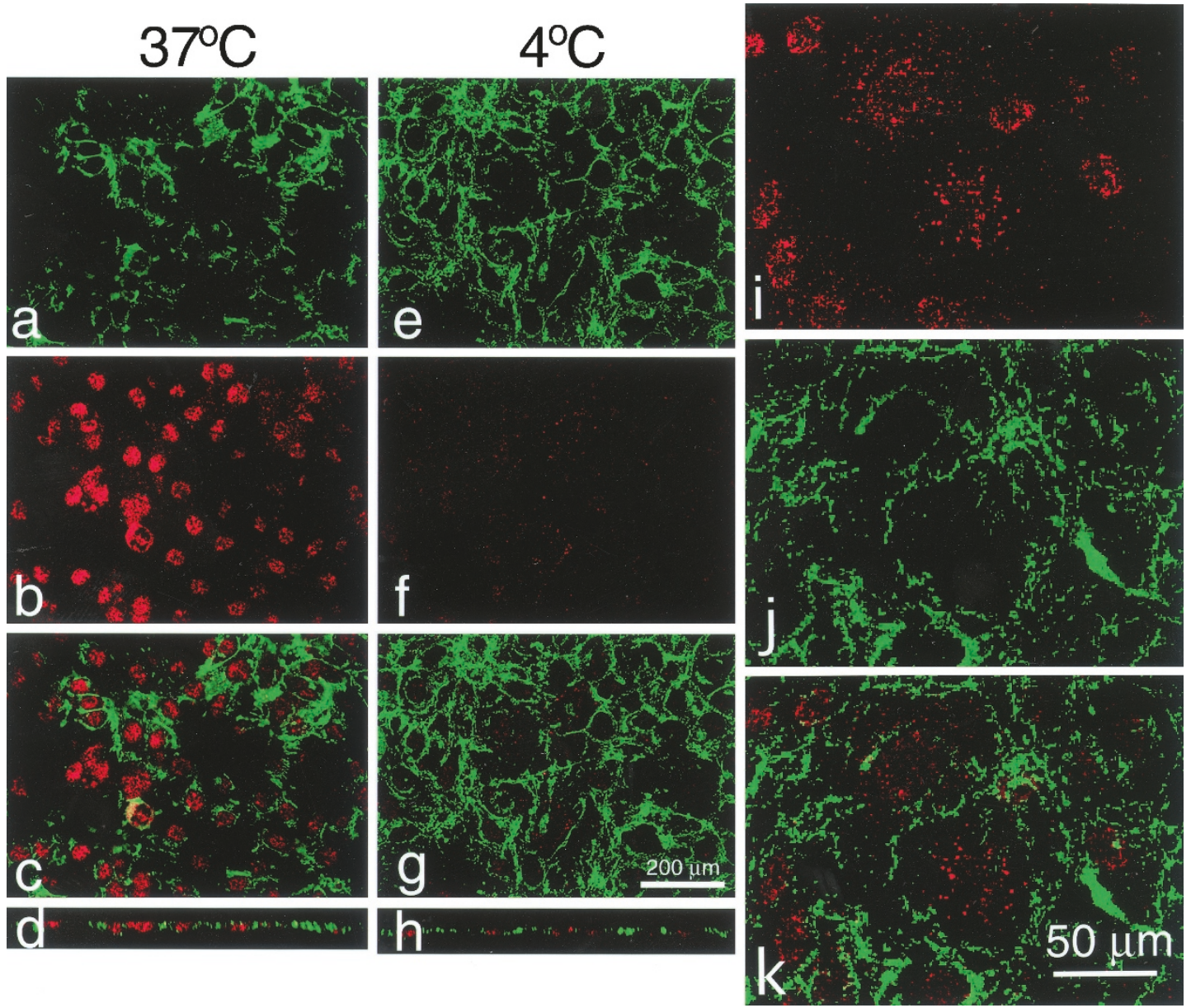

\section{Figure 3.}

EOMA cultures were incubated at $37^{\circ} \mathrm{C}\left(\mathrm{a}\right.$ to d) or preincubated for 3 hours at $4{ }^{\circ} \mathrm{C}(\mathrm{e}$ to $\mathrm{k}$ ) and double labeled with anti- $\beta$-catenin $(\mathrm{a}$, e, and j) and anti-Flk- 1 (b, $\mathrm{f}$, and i) antibodies. The merged images of both $\beta$-catenin and Flk-1 are shown in $\mathrm{c}, \mathrm{g}$, and $\mathrm{k}$. At $37^{\circ} \mathrm{C}$ a predominately nuclear localization of Flk- 1 and a discontinuous peripheral localization of $\beta$-catenin was noted (a), whereas Flk-1 exhibited mostly a nuclear localization (b). In contrast, at $4^{\circ} \mathrm{C} \beta$-catenin appeared increased at cell-cell borders (e) and Flk-1 exhibited a cytoplasmic appearance, localized to punctate structures presumed to be transport vesicles (f). The merged image of e and $\mathrm{f}$ revealed these distinct staining patterns $(\mathrm{g})$. "Z" plane sectioning through the monolayers clearly illustrates nuclear Flk-1 localization in the EOMA cells at $37^{\circ} \mathrm{C}(\mathrm{d})$ and the rather diffuse localization of Flk-1 and the more continuous peripheral localization of $\beta$-catenin upon preincubating the cells at $4{ }^{\circ} \mathrm{C}$ (h). High-power magnification of EOMA cultures incubated at $4{ }^{\circ} \mathrm{C}$ and double labeled with anti- $\beta$-catenin (j) and anti-Flk-1 (i) exhibited an Flk- 1 localization that appeared predominately cytoplasmic, localized to punctate structures presumed to be transport vesicles (i), whereas $\beta$-catenin staining revealed a mostly continuous peripheral staining pattern (j). The merged image of $\mathrm{i}$ and $\mathrm{j}$ revealed these distinct staining patterns $(\mathrm{k})$.

dition of anti-VEGF-neutralizing antibodies elicited a dramatic reduction of nuclear $\beta$-catenin (Fig. 5B) and a $40 \%$ reduction in expression of CyclinD1 (Fig. 5E), which correlates with a reduction in proliferation (Fig. 1C). In contrast, immunofluorescence analysis of HUVEC revealed minimal nuclear localization of $\beta$-catenin (Fig. 5C). Addition of VEGF elicited a modest increase in nuclear $\beta$-catenin (Fig. 5B) and a 4-fold increase in expression of CyclinD1 (Fig. 5F), which correlates with an increase in proliferation (Fig. 1C).

\section{Discussion}

The hypothesis that tumor growth is angiogenesis dependent has been documented by a considerable body of direct and indirect experimental data (Ferrara and Alitalo, 1999; Griffioen and Molena, 2000; Keshet and Ben-Sasson, 1999). Extensive efforts have been dedicated to elucidate the mechanism(s) that switch on angiogenesis and convert a dormant tumor into a rapidly growing one (Bergers et al, 2000; Hanahan and Folkman, 1996; Jiang et al, 2000; Semenza, 2000). Interestingly, however, less is known about endothelial cell tumors. Hemangiomas are benign vascular lesions and are the most common tumor of infancy (Marchuk, 2001). The incidence is $1 \%$ to $2 \%$ in neonates and $12 \%$ by the age of 1 year (Takahashi et al, 1994). Although the majority of hemangiomas require no treatment, approximately $10 \%$ become problematic, life-endangering, and even life-threatening. Most importantly, the pathogenesis of hemangioma is still not understood.

By using hemangioma-derived EOMA cells as a model system, we focused on two major systems that may affect endothelial cell proliferative behavior and cellular transformation: VEGF/VEGF receptors and cell adhesion components. EOMA, but not primary 
A

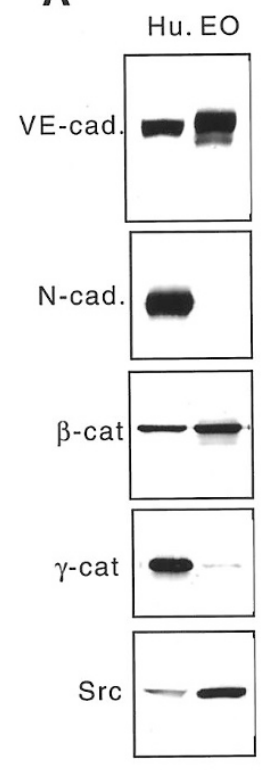

B

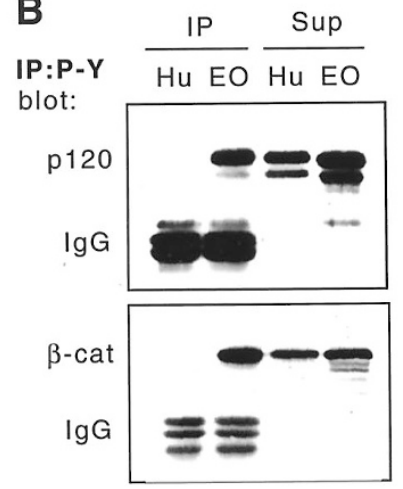

C

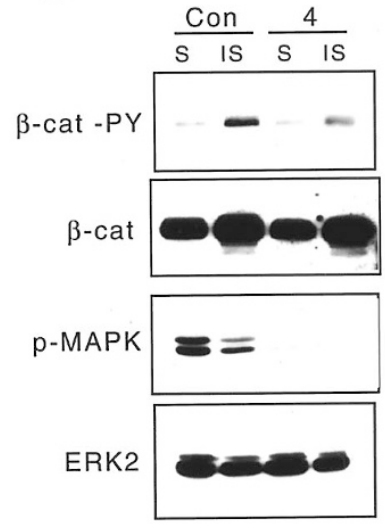

D

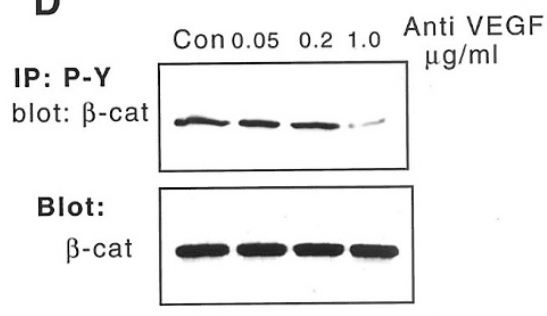

IP: P-Y blot: p120

Blot: p120

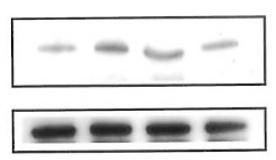

Figure 4.

Differential expression of adhesion molecules, $c$-src, and src substrates by HUVEC and EOMA. A, HUVEC $(H u)$ and EOMA (EO) cell lysates were immunoblotted with anti-VE-cadherin (VE-cad., upper panel), $\mathrm{N}$-cadherin ( $N$-cad., second panel), $\beta$-catenin ( $\beta$-cat, third panel), $\gamma$-catenin ( $\gamma$-cat, fourth panel), and src (lower panel) antibodies. B, HUVEC $(H u)$ and EOMA $(E O)$ cell lysate samples were immunoprecipitated with anti-phosphotyrosine $(P-Y$ antibodies, followed by p120 (upper panel) and $\beta$-catenin (lower panel) immunoblotting. The unprecipitated material present in the supernatant (Sup) was run in parallel to control for equal protein loading. Note the absence of tyrosine phosphorylation of p120 and $\beta$-catenin in the HUVEC lysates compared with the robust phosphorylation of these two proteins in EOMA lysates. $\mathrm{C}$, EOMA cells were left at $37^{\circ} \mathrm{C}(\mathrm{Con})$ or preincubated at $4{ }^{\circ} \mathrm{C}$ for 3 hours, and soluble $(S)$ and insoluble $(I S)$ fractions were prepared as described in "Materials and Methods." Samples were then immunoprecipitated with anti-phosphotyrosine (PY) antibodies, followed by $\beta$-catenin immunoblotting (upper panel). The same lysate samples were immunoblotted with anti- $\beta$-catenin (second panel), anti-phospho mitogen-activated protein kinase ( $p$-MAPK, third panel), and anti-Erk2 (lower panel) antibodies. Note the dramatic decrease in the insoluble, but not the soluble, $\beta$-catenin phosphorylation levels. D, EOMA cell cultures were treated with the indicated concentrations of anti-VEGF-neutralizing antibodies overnight, and lysate samples were immunoprecipitated with anti-phosphotyrosine $(P$ - $Y$ antibodies, followed by $\beta$-catenin (upper panel) and p120 (third panel) immunoblotting. The same samples were then immunoblotted with anti- $\beta$-catenin (third panel) and anti-p120 (lower panel) antibodies. Note the decrease in $\beta$-catenin but not p120 phosphorylation levels upon treatment with neutralizing anti-VEGF antibodies.

HUVEC, cells were found to express VEGF (Fig. 1B, fourth panel), in agreement with previously reported in vivo observations (Takahashi et al, 1994); this suggests that our in vitro system reflects, at least in part, the in vivo situation. This difference in VEGF expression correlated with proliferative rates of the two cell types as well as their responses to exogenous VEGF and neutralizing VEGF antibodies (Fig. 1C). In addition, modulation of VEGF levels by either sequestering endogenous VEGF or addition of recombinant VEGF correlated with the cellular localization of $\beta$-catenin and the expression of CyclinD1 (Fig. 5). Specifically, sequestration of VEGF elicited a reduction of nuclear localized $\beta$-catenin and CyclinD1 expression in EOMA cells, whereas addition of exogenous VEGF elicited an increase in nuclear localized $\beta$-catenin and CyclinD1expression in HUVEC. Thus, cellular transformation and tumorigenicity of both endothelial (EOMA) and nonendothelial tumor cells involved up-regulation of VEGF expression and secretion, acting in an autocrine manner in the context of endothelial cells.

Boye et al (2001) have recently shown that endothelial cells originated from proliferating human hemangioma are clonal and exhibit higher rates of proliferation and migration in vitro compared with normal endothelia. The different proliferative behaviors of the human-derived cells (HUVEC) compared with the murine EOMA cells (Fig. $1 \mathrm{C}$ and not shown) support the 
EOMA
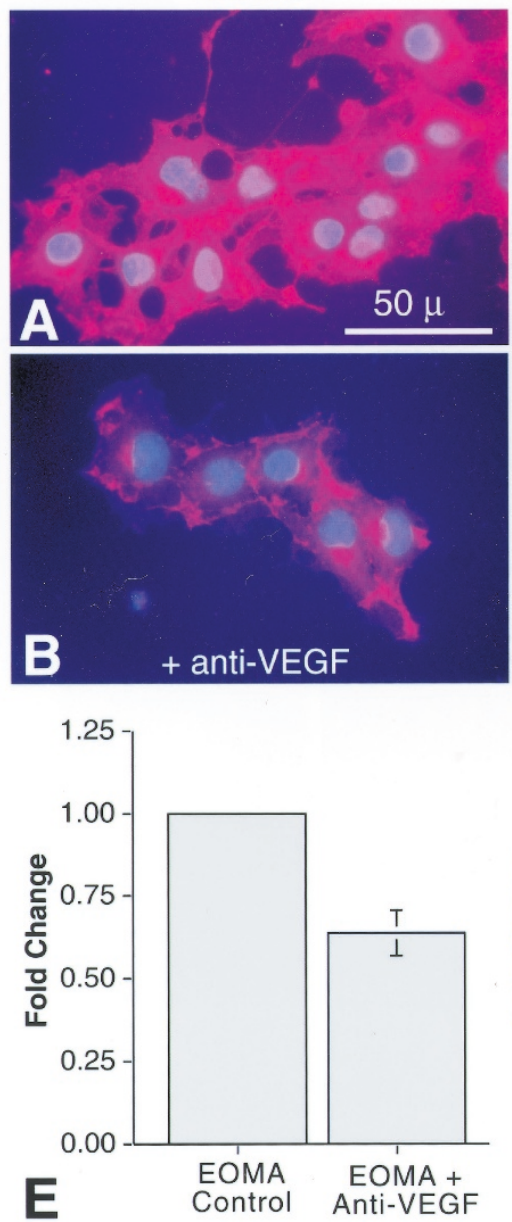

Treatment

\section{HUVEC}
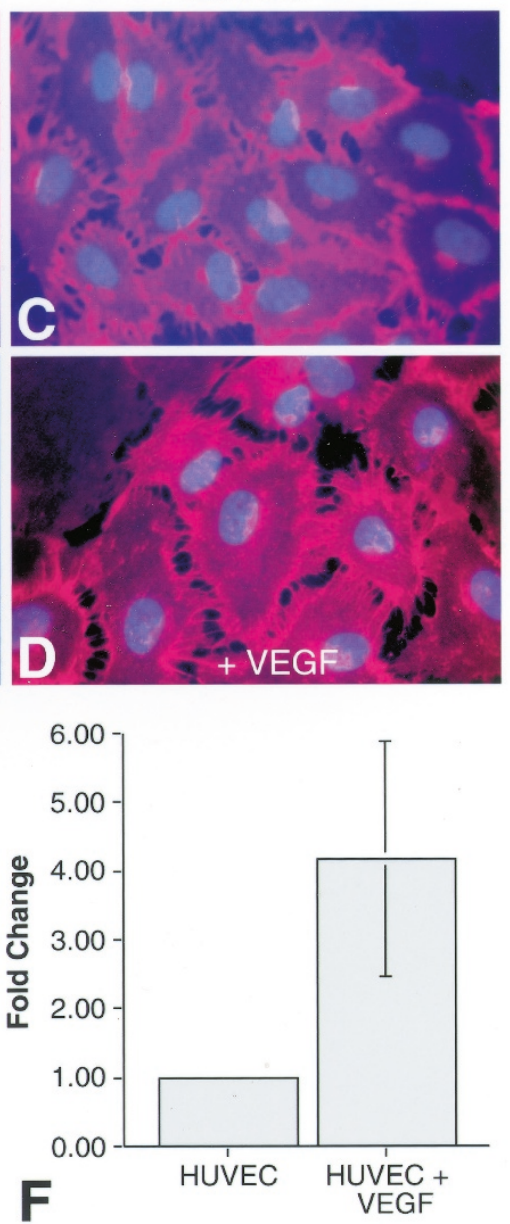

Treatment

Figure 5 .

VEGF level modulates $\beta$-catenin localization and signaling pathway activation. A, Subconfuent EOMA cells were stained with anti- $\beta$-catenin (red fluorescence) and 4,6-diamidino-2-phenylindole (DAPI) (blue fluorescence). Note the robust nuclear $\beta$-catenin (purple fluorescence). B, Subconfuent EOMA cells treated with 1.0 $\mu$ g/ml anti-VEGF-neutralizing antibody were stained with anti- $\beta$-catenin (red fluorescence) and DAPI (blue fluorescence). Note the absence of nuclear $\beta$-catenin. C, Subconfuent HUVEC cells were stained with anti- $\beta$-catenin (red fluorescence) and DAPI (blue fluorescence). Note the paucity of nuclear $\beta$-catenin. D, Subconfuent HUVEC cells treated with $10 \mathrm{ng} / \mathrm{ml}$ VEGF were stained with anti- $\beta$-catenin (red fluorescence) and DAPI (blue fluorescence). Note the presence of nuclear $\beta$-catenin (purple fluorescence). E, Western blot analysis of CyclinD1 expression in EOMA cells. Note the $40 \%$ reduction in expression after treatment with anti-VEGFneutralizing antibody $(n=3, p<0.05)$. F, Western blot analysis of CyclinD1 expression in HUVEC cells. Note the 4-fold increase in expression after treatment with $\operatorname{VEGF}(n=3, p<0.05)$.

relevance of our EOMA model. Furthermore, after activation of Flk-1 by VEGF, differences in Flk-1 and $\beta$-catenin localization were noted. Specifically, in HUVEC the majority of the Flk-1 remained localized to the periphery of the cell (cortical membrane) (llan et al, 1999 and Fig. 2); in EOMA cells, Flk-1 exhibited a nuclear localization (Figs. 2 and 3), as was previously noted for VEGF-stimulated bovine aorta endothelial cells (Feng et al, 1999). The constitutive Flk nuclear localization noted in EOMA cells stands in contrast with the transient Flk translocation observed by Feng et al (1999) and is consistent with the continuous autocrine VEGF loop in EOMA cells. Interestingly, not only the receptors, but also VEGF itself have been noted to accumulate in the nucleus (Li and Keller, 2000), suggesting that VEGF and its receptor may translocate as a complex.
The role that VEGF-FIk/Flt may play in the nucleus is not yet known but may involve Flk/Flt adapter proteins, such as $\beta$-catenin. Indeed, $\beta$-catenin was found to be constitutively associated with Flk and Flt in EOMA cells (Fig. 1, A and B), as was previously noted in transformed endothelial cells (Carmeliet et al, 1999), and colocalized in the nucleus with Flk-1 in EOMA cells in response to constitutive autocrine VEGF stimulation (Fig. 5). Thus, Flk/Flt $\beta$-catenin association seems to be a more general characteristic of transformed endothelial cells. Moreover, markedly different $\beta$-catenin localization and tyrosine phosphorylation patterns were noted in HUVEC. In HUVEC, $\beta$-catenin was localized to the periphery of the cells in a cortical membrane distribution, similar to and colocalizing with Flk-1 (Figs. 2, 3, and 5) (llan et al, 1999), and displayed a low tyrosine phosphorylation level (Fig. 4B). In con- 
trast, in EOMA cells, a fraction of $\beta$-catenin was localized to the cell periphery, presumably at cell-cell contact sites. Much of the $\beta$-catenin was noted to assume perinuclear and nuclear localization, exhibiting partial colocalization with Flk-1 (Figs. 2, 3, and 5), where it presumably interacts with LEF/TCF transcription factors and affects gene expression (Barth et al, 1997; Ben-Ze'ev and Geiger, 1998) (as evidenced by the changes in CyclinD1 expression illustrated in Fig. 5). Such dramatic changes in localization correlate with a robust increase in $\beta$-catenin tyrosine phosphorylation levels (Fig. 4B), likely but not certain to be due to the direct action of Flk (Fig. 1E).

Indeed, the insoluble $\beta$-catenin fraction is the most tyrosine phosphorylated, and phosphorylation levels were dramatically reduced upon incubation at $4^{\circ} \mathrm{C}$ (Fig. 4C), suggesting that $\beta$-catenin phosphorylation occurred at the plasma membrane, resulting in discontinuous and immature cell-cell contacts (Figs. 2 and 3). Recently, tyrosine 654 has been characterized as the $\beta$-catenin residue that most affects the interaction with E-cadherin (Piedra et al, 2001; Roura et al, 1999) and accounts for cell adhesion disruption. It would be interesting to determine whether this residue is a substrate for Flk/Flt and how it may affect endothelial cell behaviors such as junctional complex formation and integrity, proliferation, and permeability. Interestingly, the mitogen-activated protein kinase (MAPK) pathway is also up-regulated in EOMA cells (Fig. $4 \mathrm{C}$ and not shown), in agreement with and as part of the VEGF signaling cascade (Berra et al, 2000; D'Angelo et al, 1995; Ilan et al, 1998). Although most of the active, phosphorylated, MAPK molecules are found in the soluble fraction, about $10 \%$ to $15 \%$ are found to be insoluble (Fig. 4C, third panel), suggesting partial localization to cadherin-catenin-actin or other cytoskeletal complexes.

Cell adhesion plays a critical role in the development and maintenance of complex differentiated epithelial tissues (Takeichi, 1995). It is now apparent that the hallmarks of epithelial malignancy such as uncontrolled proliferation, invasion, and colonization to distant organs can be explained, at least in part, by alteration in the adhesive properties of neoplastic cells (Perl et al, 1998; Vleminckx et al, 1991; Yap, 1998). Cadherin-mediated cell-cell adhesion is a common process observed in many tissues and cell types and involves complex protein-protein interactions mediating stable interaction with the actin cytoskeleton necessary for cadherin function. $\beta$ - and $\gamma$-catenin bind to the catenin-binding domain of the cadherin cytoplasmic tail and physically mediate the cytoskeleton connection. In contrast, p120 binds to the juxtamembrane domain and is thought to regulate the assembly and disassembly of adherens junctions by different mechanism(s). Tyrosine phosphorylation of adherens junctions' components, mainly catenins, has been often correlated with a decrease in cell adhesion and an increase in invasiveness (Behrens et al, 1993; Daniel and Reynolds, 1997; Kinch et al, 1995; Playford et al, 2000). Hyper $\beta$-catenin tyrosine phosphorylation levels previously noted in EOMA cells (Ilan et al, 1999) and further confirmed here (Fig. 4B), may explain the poor adherens junction formation in EOMA cells (Figs. 2 and 3$)$.

A better understanding of junctional complexes was obtained by a careful examination of the multiple components of adherens junctions in EOMA cells. Interestingly, although VE-cadherin expression levels were up-regulated, $\mathrm{N}$-cadherin and $\gamma$-catenin were practically absent in EOMA cells (Fig. 4A). Thus, most components of adherens junctions in EOMA cells are either absent ( $\mathrm{N}$-cadherin, $\gamma$-catenin) or highly tyrosine phosphorylated $(\beta$ catenin, p120), resulting in adherens junctions disassembly. However, in contrast to epithelia and other cell types, endothelia have an additional cell adhesion system mediated by PECAM-1. We have previously reported that PECAM-1 preferentially binds tyrosine-phosphorylated $\beta$-catenin (Ilan et al, 1999) and regulates $\beta$-catenin phosphorylation levels, presumably by PECAM-1-bound protein tyrosine phosphatase (SHP-2) (llan et al, 2001). By doing so, PECAM-1 may function to stabilize the endothelium by regulating, in part, $\beta$-catenin participation in adherens junction dynamics (Graesser et al, 2002; Gratzinger et al, 2003). In a recent study using PECAM-1deficient and reconstituted endothelial cells and 293 cells, we have demonstrated that the presence of PECAM-1 modulates the cellular distribution of $\beta$-catenin (enhancing nuclear localization) and increases its transcriptional activity (increasing TOPflash luciferase activity) and cellular proliferation (Biswas et al, 2003). This data, coupled with previous data (Carmeliet et al, 1999; Lampugnani and Dejana, 1997; Ogunshola et al, 2000; Ilan et al, 1999), are consistent with the notion that VEGF levels determine, in part, specific cellular phenotypes (increased proliferative rates in the case of EOMA cells) via VEGFRmediated changes in expression and phosphorylation of selected proteins including $\beta$-catenin.

The further use of the EOMA model system presented here may give us the opportunity to further analyze the possible involvement of several cell adhesion and cytoskeletal components in selected endothelial cell behaviors such as junctional complex formation, integrity, permeability, migration, and proliferation.

\section{Materials and Methods}

\section{Cells and Cell Cultures}

HUVEC were obtained from Jordan Pober (Yale Medical School) and were cultured in gelatin-coated flasks as described (Ilan et al, 1998, 1999). Hemangioendothelioma (EOMA) cells were obtained from Robert Auerbach (University of Wisconsin, Madison, Wisconsin (Obeso et al, 1990) and were grown in complete DMEM supplemented with $10 \%$ fetal bovine serum and antibiotics, as described (Ilan et al, 1999).

\section{Cell Proliferation Assay}

Cell proliferation was determined by cell counting using a Coulter counter as previously described (Form 
et al, 1986). Briefly, $4.0 \times 10^{4}$ cells were plated in $60-\mathrm{mm}$ bovine calf skin type I collagen-coated Petri dishes. Cells were allowed to proliferate in the presence and absence of $10 \mathrm{ng} / \mathrm{ml}$ VEGF- $A_{165}$ and 1.0 $\mu \mathrm{g} / \mathrm{ml}$ anti-VEGF neutralizing antibody. At Days 3 and 6 , triplicate samples were counted. Statistical significance was determined using the Student's $t$ test.

\section{Cell Lysate Preparation, Immunoprecipitation, and Protein Blotting}

Cell cultures were pretreated with $1 \mathrm{~mm}$ orthovanadate for 15 minutes at $37^{\circ} \mathrm{C}$, washed twice with ice-cold PBS containing $1 \mathrm{~mm}$ orthovanadate, and scraped into lysis buffer [50 mm Tris, $\mathrm{pH} 7.4,150 \mathrm{~mm} \mathrm{NaCl,} 1 \%$ Triton-X100, 1\% NP-40, 0.5\% deoxycholate, $1 \mathrm{~mm}$ orthovanadate, $1 \mathrm{~mm}$ phenylmethylsulfonyl fluoride, and a mixture of proteinase inhibitors (Boehringer Mannheim, GmbH, Germany)]. Soluble and insoluble cell fractions were prepared as previously described (llan et al, 1999). Total cellular protein concentration was determined by the BCA assay (Pierce, Rockford, Illinois), according to the manufacturer's instructions. Twenty micrograms of cellular protein were fractionated on SDS polyacrylamide gels, and protein immunoblotting was performed as described (llan et al, 1998). For immunoprecipitation, $100 \mu \mathrm{g}$ of cellular protein were brought to a volume of $1.0 \mathrm{ml}$ in buffer containing $50 \mathrm{~mm}$ Tris, $\mathrm{pH} 7.5,0.15 \mathrm{M} \mathrm{NaCl}, 5 \mathrm{~mm}$ EDTA, and $0.5 \%$ NP-40, preabsorbed with normal rabbit serum followed by protein A/G-Sepharose (Santa Cruz Biotechnology, Santa Cruz, California) precipitation. The cleared supernatant was incubated with the appropriate antibody for 2 hours on ice followed by protein A/G-Sepharose immunoprecipitation. Beads were washed three times with the same buffer supplemented with $5 \%$ sucrose and once with the same buffer without sucrose and reduced salt concentration (50 mM NaCl). Sample buffer was then added, and after boiling samples were subjected to gel electrophoresis and immunodetection as described.

\section{In Vitro Immune Complex Kinase Assay}

Flk-1 kinase activity in immune complexes was determined according to the protocol of Kroll and Waltenberger (1997). Confluent, nonstimulated HUVEC and EOMA cell cultures were pretreated with $1 \mathrm{~mm}$ orthovanadate for 15 minutes, washed with ice-cold PBS containing $0.1 \mathrm{~mm}$ vanadate, and solubilized in lysis buffer containing $150 \mathrm{~mm} \mathrm{NaCl,} 20 \mathrm{~mm}$ Tris- $\mathrm{HCl}$, $\mathrm{pH} 7.4,1 \% 3$ 3-[(3-cholamidopropyl)dimethylammonio]1-propane-sulfonate, $10 \%$ glycerol, $1 \mathrm{~mm}$ phenylmethylsulfonyl fluoride, and a mixture of protease inhibitors (Boehringer Mannheim). Two hundred micrograms of cleared cell lysates were immunoprecipitated with anti-Flk-1 antibodies (sc-504; Santa Cruz) as described, and kinase assay was performed for 15 minutes at room temperature in $25 \mu \mathrm{l}$ of $50 \mathrm{~mm}$ HEPES, pH 7.4, $10 \mathrm{~mm} \mathrm{MnCl,} \mathrm{10 \%} \mathrm{glycerol,} \mathrm{and} 5 \mu \mathrm{Ci}$ of $\left[\gamma^{-32}\right.$ P]ATP (New England Nuclear Research Products, Boston, Massachusetts), with or without the addition of $1 \mu \mathrm{g}$ purified, recombinant, $\beta$-catenin (llan et al, 1999). Half the reaction was subjected to gel electrophoresis, and the dried gel was exposed to Hyperfilm MP (Amersham, Arlington Heights, Illinois).

\section{Antibodies and Reagents}

Rabbit polyclonal antibodies to human and mouse PECAM-1 have been described previously (llan et al, 1999, 2000). Anti-phosphotyrosine (PY99), antiphospho MAPK (E-4), anti-Erk 2 (C14), anti-src (SRK 2), anti-VEGF (sc-507), anti-Flk-1 (sc-504), and antiFlt-1 (sc-316) antibodies were purchased from Santa Cruz. mAbs to $\beta$-catenin, $\gamma$-catenin, and $\mathrm{p} 120$ were purchased from Transduction Laboratories (Lexington, Kentucky); VEGF and neutralizing VEGF antibodies were purchased from R\&D Systems (Minneapolis, Minnesota). Anti- $\beta$-actin was purchased from Sigma (St. Louis, Missouri). Polyclonal antibodies to VEcadherin were kindly provided by Dr. Robert Wysolmerski (St. Louis University, St. Louis, Missouri) and anti-N-cadherin was kindly provided by Dr. Margaret Wheelock (University of Ohio, Toledo, Ohio). Anti-CyclinD1 antibodies (sc-718) were purchased from Santa Cruz.

\section{Confocal Microscopy}

Traditional immunofluorescence microscopy was performed using a Zeiss Standard Research Microscope equipped with Rhodamine and Fluorescein filter sets and SPOT digital camera. Confocal microscopy was performed using an Olympus IX70 inverted fluorescence microscope outfitted with Olympus Fluoview Argon/Krypton scanning laser system and Fluoview image analysis software (Olympus, Melville, New York). Unedited images were transferred to Photoshop 5.05 and printed on an Epson 980 color printer.

\section{Statistics}

Results were analyzed using Student's $t$ test and ANOVA. Significance was assumed when $p<0.05$.

\section{Acknowledgement}

The authors thank Mr. Sepi Mahooti for excellent technical assistance.

\section{References}

Abedi H and Zachary I (1997). Vascular endothelial growth factor stimulates tyrosine phosphorylation and recruitment to new focal adhesions of focal adhesion kinase and paxillin in endothelial cells. J Biol Chem 272:15442-15451.

Arbiser J, Larsson H, Claesson-Welsh L, Bai X, LaMonagen K, Weiss W, Soker S, Flynn E, and Brown L (2000). Overexpression of VEGF 121 in immortalized endothelial cells causes conversion to slowly growing angiosarcoma and high level expression of the VEGF receptors VEGFR-1 and VEGFR-2 in vivo. Am J Pathol 156:1469-1476.

Barth A, Nathke I, and Nelson W (1997). Cadherins, catenins and APC protein: Interplay between cytoskeletal complexes and signaling pathways. Curr Opin Cell Biol 9:683-690. 
Behrens J, Vakaet L, Frriis R, Winterhager E, Van Roy F, Mareel M, and Birchmeier W (1993). Loss of epithelial differentiation and gain of invasiveness correlates with tyrosine phosphorylation of the E-cadherin/beta-catenin complex in cells transformed with a temperature-sensitive v-SRC gene. J Cell Biol 120:757-766.

Ben-Ze'ev A and Geiger B (1998). Differential molecular interactions of beta-catenin and plakoglobin in adhesion, signaling and cancer. Curr Opin Cell Biol 10:629-639.

Bergers G, Brekken R, McMahon G, Vu T, Itoh T, Tamaki K, Tanzawa K, Thorpe P, Itohara S, Werb Z, and Hanahan D (2000). Matrix metalloproteinase- 9 triggers the angiogenic switch during carcinogenesis. Nat Cell Biol 2:737-744.

Berra E, Milanini J, Richard D, Le Gall N, Vinals F, Gothie E, Page SG, and Pouyssegur J (2000). Signaling angiogenesis via $42 / p 44$ MAP kinase and hypoxia. Biochem Pharmacol 60:1171-1178.

Biswas P, Canosa S, Schoenfeld J, Schoenfeld D, Tucker A, and Madri JA (2003). PECAM-1 promotes $\beta$-catenin accumulation and stimulates endothelial cell proliferation. Biochem Biophys Res Commun 303:212-218.

Bohling T, Hatva E, Kujala M, Claesson-Walsh L, Alitalo K, and Halti M (1996). Expression of growth factors and growth factor receptors in capillary hemangioblastoma. J Neuropathol Exp Neurol 55:522-527.

Boye E, Yu Y, Paranya G, Mulliken J, Olson B, and Bischoff $J$ (2001). Clonality and altered behavior of endothelial cells from hemangiomas. J Clin Invest 107:745-752.

Carmeliet P, Lampugnani MG, Moon L, Breviario F, Compernolle V, Bono F, Balconi G, Spagnuolo R, Oostuyes B, Dewerchin M, Zanetti A, Angellilo A, Mattot V, Nuyens D, Lutgens E, Clotman F, deRuiter M, Gittenberger-de Groot A, Poelman R, Lupu F, Herbert J, Collen D, and Dejana E (1999). Targeted deficiency or cytosolic truncation of the VEcadherin gene in mice impairs VEGF-mediated endothelial survival and angiogenesis. Cell 98:147-157.

Cross M and Claesson-Welsh L (2001). FGF and VEGF function in angiogenesis: Signalling pathways, biological responses and therapeutic inhibition. Trends Pharmacol 22: 201-207.

D'Angelo G, Struman I, Martial J, and Weiner R (1995). Activation of mitogen-activated protein kinases by vascular endothelial growth factor and basic fibroblast growth factor in capillary endothelial cells is inhibited by the antiangiogenic factor $16-\mathrm{kDa} \mathrm{N}$-terminal fragment of prolactin. Proc Natl Acad Sci USA 92:6374-6378.

Daniel J and Reynolds A (1997). Tyrosine phosphorylation and cadherin/catenin function. Bioessays 19:1883-1889.

Dougher M and Terman B (1999). Autophosphorylation of $\mathrm{KDR}$ in the kinase domain is required for maximal VEGFstimulated kinase activity and receptor internalization. Oncogene 18:1619-1627.

Esser S, Lampugnani M, Corada M, Dejana E, and Risau W (1998). Vascular endothelial growth factor induces VEcadherin tyrosine phosphorylation in endothelial cells. J Cell Sci 111:1853-1865.

Feng Y, Venema V, Venema R, Tsai N, and Caldwell R (1999). VEGF induces nuclear translocation of Flk-1/KDR, endothelial nitric oxide synthase, and caveolin-1 in vascular endothelial cells. Biochem Biophys Res Commun 256:192-197.
Ferrara N and Alitalo K (1999). Clinical applications of angiogenic growth factors and their inhibitors. Nat Med 12:13591364.

Ferrara N and Davis-Smyth T (1997). The biology of vascular endothelial growth factor. Endocrine Rev 18:4-25.

Form D, Pratt B, and Madri J (1986). Endothelial cell proliferation during angiogenesis: In vitro modulation by basement membrane components. Lab Invest 55:521-530.

Gotoh J, Obata M, Yoshie M, Kasai S, and Ogawa K (2003). Cyclin D1 over-expression correlates with beta-catenin activation, but not with $\mathrm{H}$-ras mutations, and phosphorylation of Akt, GSK3beta and ERK1/2 in mouse hepatic carcinogenesis. Carcinogenesis 3:435-442.

Graesser D, Solowiej A, Bruckner M, Osterweil E, Judes AM, Davis S, Ruddle N, Engelhardt B, and Madri JA (2002). Altered vascular permeability and early onset of experimental autoimmune encephalomyelitis in PECAM-1-deficient mice. J Clin Invest 109:383-392.

Gratzinger D, Barreuther M, and Madri JA (2003). Plateletendothelial cell adhesion molecule-1 modulates endothelial migration through its immunoreceptor tyrosine-based inhibitory motif. Biochem Biophys Res Commun 301:243-249.

Griffioen A and Molema G (2000). Angiogenesis: Potentials for pharmacologic intervention in the treatment of cancer, cardiovascular diseases, and chronic inflammation. Pharmacol Rev 52:237-268.

Hanahan D and Folkman J (1996). Patterns and emerging mechanisms of the angiogenic switch during tumorigenesis. Cell 86:353-364.

Hashimoto M, Ohsawa M, Ohnishi A, Naka N, Hirota S, Kitamura Y, and Aozasa K (1995). Expression of vascular endothelial growth factor and its receptor mRNA in angiosarcoma. Lab Invest 73:859-863.

Hatva E, Bohling T, Jaaskelainen J, Persico M, Haltia M, and Alitalo K (1996). Vascular growth factors and receptors in capillary hemangioblastomas and hemangiopericytomas. Am J Pathol 148:763-775.

Ilan N, Cheung L, Miller S, Mohsenin A, Tucker A, and Madri $J$ (2001). PECAM-1 is a modulator of stat family member phosphorylation and localization: Lessons from a transgenic mouse. Dev Biol 232:219-232.

Ilan N, Cheung L, Pinter E, and Madri J (2000). Plateletendothelial cell adhesion molecule-1 (CD31), a scaffolding molecule for selected catenin family members whose binding is mediated by different tyrosine and serine/threonine phosphorylation. J Biol Chem 275:21435-21443.

Ilan N, Mahooti S, and Madri J (1998). Distinct signal transduction pathways are utilized during the tube formation and survival phases of in vitro angiogenesis. J Cell Sci 111:36213631.

llan N, Mahooti S, Rimm D, and Madri J (1999). PECAM-1 (CD31) functions as a reservoir for and a modulator of tyrosine-phosphorylated beta-catenin. J Cell Sci 112:30053014.

Jiang C, Ganther H, and Lu J (2000). Monomethyl seleniumspecific inhibition of MMP-2 and VEGF expression: Implications for angiogenic switch regulation. Mol Carcinog 29:236250.

Keshet E and Ben-Sasson S (1999). Anticancer drug targets: Approaching angiogenesis. J Clin Invest 104:1497-1501. 
Kevil C, Payne D, Mire E, and Alexander J (1998). Vascular permeability factor/vascular endothelial cell growth factormediated permeability occurs through disorganization of endothelial junctional proteins. J Biol Chem 273:1509915103.

Kinch M, Clark G, Der C, and Burridge K (1995). Tyrosine phosphorylation regulates the adhesions of ras-transformed breast epithelia. J Cell Biol 130:461-471.

Kroll $\mathrm{J}$ and Waltenberger J (1997). The vascular endothelial growth factor receptor KDR activates multiple signal transduction pathways in porcine aortic endothelial cells. J Biol Chem 272:32521-32527.

Lampugnani M and Dejana E (1997). Interendothelial junctions: Structure, signalling and functional roles. Curr Opin Cell Biol 9:674-682.

Li W and Keller G (2000). VEGF nuclear accumulation correlates with phenotypical changes in endothelial cells. J Cell Sci 113:1525-1534.

Marchuk D (2001). Pathogenesis of hemangioma. J Clin Invest 107:665-666.

Maru Y, Hirosawa H, and Shibuya M (2000). An oncogenic form of the Flt-1 kinase has a tubulogenic potential in a sinusoidal endothelial cell line. Eur J Cell Biol 79:130-143.

Muhlner U, Mohle-Stinlein U, Wizigmann-Voos S, Christofori G, Risau W, and Wagner E (1999). Formation of transformed endothelial cells in the absence of VEGFR-2/Flk-1 by polyoma middle T oncogene. Oncogene 18:4200-4210.

Obeso J, Weber J, and Auerbach R (1990). A hemangioendothelioma-derived cell line: Its use as a model for the study of endothelial cell biology. Lab Invest 63:259269.

Ogunshola O, Stewart WB, Mihalcik V, Solli T, Madri JA, and Ment LR (2000). Neuronal VEGF mediates angiogenesis in postnatal developing rat brain. Dev Brain Res 119:139-153.
Perl A, Wilgenbus P, Dahl U, Semb H, and Christofori G (1998). A causal role for E-cadherin in the transition from adenoma to carcinoma. Nature 392:190-193.

Piedra J, Martinez D, Castano J, Miravet S, Dunach M, and de Herrero A (2001). Regulation of beta-catenin structure and activity by tyrosine phosphorylation. J Biol Chem 276: 20436-20443.

Playford M, Bicknell D, Bodmer W, and Macaulay V (2000). Insulin-like growth factor 1 regulates the location, stability, and transcriptional activity of beta-catenin. Proc Natl Acad Sci USA 97:12103-12108.

Reynolds A, Roesel D, Kanner S, and Parsons J (1989). Transformation-specific tyrosine phosphorylation of a novel cellular protein in chicken cells expressing oncogenic variants of the avian cellular src gene. Mol Cell Biol 9:629-638.

Roura S, Miravet S, Piedra J, de Herreros A, and Dunach M (1999). Regulation of E-cadherin/catenin association by tyrosine phosphorylation. J Biol Chem 274:36734-36740.

Semenza G (2000). HIF-1: Using two hands to flip the angiogenic switch. Cancer Metastasis Rev 19:59-65.

Takahashi K, Mulliken J, Kozakewich H, Rogers R, Folkman $\mathrm{J}$, and Ezekowitz A (1994). Cellular markers that distinguish the phases of hemangioma during infancy and childhood. J Clin Invest 93:2357-2364.

Takeichi M (1995). Morphogenetic roles of classic cadherins. Curr Opin Cell Biol 7:619-627.

Vleminckx K, Vakaet L, Mareel M, Fires W, and van Roy F (1991). Genetic manipulation of E-cadherin expression by epithelial tumor cells reveals an invasion suppressor role. Cell 66:107-119.

Yap AS (1998). The morphogenetic role of cadherin cell adhesion molecules in human cancer: A thematic review. Cancer Invest 16:252-261. 